\title{
A COMPARISON OF ESSENTIAL OIL CONSTITUENTS OF BARK, LEAF, ROOT AND FRUIT OF CINNAMON (CINNAMOMUM ZEYLANICUM BLUM) GROWN IN SRI LANKA.
}

\author{
P. A. PARANAGAMA ${ }^{1 *}$, S. WIMALASENA ${ }^{1}$, G. S. JAYATILAKE ${ }^{2}$, A. L. \\ JAYAWARDENA ${ }^{2}$, U. M. SENANAYAKE ${ }^{2}$ and A. M. MUBARAK ${ }^{2}$ \\ ${ }^{1}$ Department of Chemistry, University of Kelaniya, Kelaniya. \\ ${ }^{2}$ ITI, Colombo-07.
}

(Received: 23 January 2001; accepted: 30 January 2002)

\begin{abstract}
The essential oils of the bark, leaf, root and fruit of Cinnamon were analyzed by capillary GC and GC/MS. The major constituents of Cinnamon fruit oil, were $\delta$ and $\gamma$ - cadinene $(36.0 \%)$ and $\mathrm{T}$ - cadinol $(7.7 \%)$ and $\beta$-caryophyllene $(5.6 \%)$. About $84 \%$ of Cinnamon fruit oil comprised sesquiterpenes while other parts of Cinnamon contained less than $9 \%$ of this group of compounds. Phenyl propanoids were the major constituents of Cinnamon bark and leaf oils while root oil had monoterpenes as the major constituents $(95 \%)$.
\end{abstract}

Key words: cadinene, camphor, Cinnamomum zeylanicum, cinnamaldehyde, essential oil, eugenol, Lauraceae.

\section{INTRODUCTION}

Cinnamon (Cinnamomum zeylanicum Blum) an endemic plant popularly known as "Kurundu" in Sri Lanka belongs to the genus Cinnamomum of the plant family Lauraceae. ${ }^{1}$ It is also found in the southern parts of India, China, Burma and Indonesia. Cinnamon bark is used as a spice to improve flavor of local food preparations. Cinnamon bark and leaf oils are used as flavor ingredients and also in cosmetics and pharmaceutical preparations. ${ }^{2,3}$

Previous studies have shown that Cinnamon bark, leaf and root oils differ significantly in their chemical composition with cinnamaldehyde, eugenol and camphor being the major constituents respectively. ${ }^{4}$ This unique property of Cinnamon has given rise to much interest in the biosynthetic pathways of their chemical constituents. Thus Cinnamon offers a variety of oils with different aroma characteristics and compositions to the flavor industry. The root bark was reported to have camphor as the main constituent ${ }^{5}$, but it does not seem to have commercial value unlike the leaf and bark oils. The fruits of the Cinnamon plant are also aromatic and possess a sweet spicy aroma. It was reported that the fruits of Cinnamon grown in different regions in India are of two types ${ }^{6,7}$, one having $\beta$-caryophyllene and $(\mathrm{E})$ cinnamyl acetate as the major constituents and the other having $\alpha$-pinene, $\beta$ caryophyllene, $\delta$-cadinene and $\alpha$-muurolol as the major constituents in the oils

${ }^{*}$ Corresponding author 
investigated. ${ }^{6,7}$ The volatile constituents of fruits of Cinnamon grown in Sri Lanka have not been studied previously and we now report the identification of Cinnamon fruit oil constituents and compare it with the root, bark, and leaf oils.

\section{METHODS AND MATERIALS}

Sample preparation: Fresh fruits, bark, leaves and roots of Cinnamon were collected from an estate in Hikkaduwa, Sri Lanka. Air-dried samples were hydrodistilled using a Clevenger light oil apparatus and a modified Likens and Nickerson apparatus. $^{8}$

GC; FID-GC: Bonded phase Supelcowax 10 and SPB-1 fused silica capillary columns, $30 \mathrm{~m} \times 0.32 \mathrm{~mm} ; 0.25 \mu \mathrm{m}$ film thickness. The column was programmed as follows: $50^{\circ} \mathrm{C}(2 \mathrm{~min}), 50^{\circ} \mathrm{C}-210^{\circ} \mathrm{C}$ at $2^{\circ} \mathrm{C} / \mathrm{min}, 210^{\circ} \mathrm{C}(30 \mathrm{~min})$ with a Helium carrier gas. The injector and detector temperatures were $250^{\circ} \mathrm{C}$ and $0.1 \mu \mathrm{l}$ of the oil was injected using a Grob sampler in splitless mode with a sampling time of $0.5 \mathrm{~min}$. Area percentages for the components were obtained with a data processor.

GC/MS; GC conditions were as above with $\mathrm{He}$ as carrier gas; direct interface at $250^{\circ} \mathrm{C}$; ionization voltage $70 \mathrm{eV}$, ion source temp. $250{ }^{\circ} \mathrm{C}$. Individual constituents were identified by comparison of their mass spectra and retention indices with literature data. The experimental work was carried out in triplicate.

\section{RESULTS}

The hydrodistillation of the bark, leaf, root and fruit of Cinnamon separately gave pale yellow oils with a pleasant, spicy odor. The yields were $1.2 \%, 0.75 \%, 2.0 \%$ and $0.5 \%$ respectively.

The components, identified by GC/MS and relative retention times in the essential oils of Cinnamon bark, leaf, root and fruit oils are listed in Table 1. At least 37 compounds were detected in Cinnamon bark oil of which 35 were identified. Most of the compounds have been reported previously in Cinnamon bark oil but $\alpha$ ylangene $(0.7 \%)$ is reported for the first time. In Cinnamon leaf oil of the 32 compounds detected, 29 were identified. At least 46 compounds were detected in the root oil of which 37 compounds were identified. Sabinol, citronellyl formate, P-cymene-7-ol and methoxy eugenol are reported as new compounds in Cinnamon root oil.

Cinnamon fruit oil, not previously studied in Sri Lanka, contained 57 detectable compounds of which 49 were identified. The major constituents $\delta$ and $\gamma$ cadinene accounted for around $36 \%$ of the oil. The oil was also rich in sesquiterpenes containing $67 \%$ sesquiterpene hydrocarbons and $17 \%$ sesquiterpene alcohols. Phenyl proponoids, the major constituents in bark and leaf oils were present only in small 
amounts (1\%). Twenty one sesquiterpenes (83.6\%), eighteen monoterpenes (6.7\%) and seven phenyl proponoids $(0.9 \%)$ were identified in fruit oil.

Amounts of monoterpenes, sesquiterpenes and phenyl proponoids fractions in bark, leaf, root and fruit oils are given in Table 2. The phenyl proponoid fraction was prominent in leaf and bark oils, amounting to $85.4 \%$ and $64.8 \%$ respectively but present in very low levels in root and fruit oils (2.2\% and $0.9 \%$ respectively). On the other hand Cinnamon fruit oil was found to be rich in sesquiterpenes (83.6\%) while Cinnamon root oil contained more than $95 \%$ of monoterpenes.

Table 1: Constituents of Cinnamon fruit, bark, leaf and root oils

\begin{tabular}{lllll}
\hline Compound & \multicolumn{4}{c}{ Relative abundance } \\
\cline { 2 - 5 } & Fruit & Bark & Leaf & Root \\
\hline$\alpha$-Pinene & 2.19 & 3.34 & 0.73 & 5.70 \\
Unknown & - & 1.10 & 0.08 & 0.57 \\
Camphene & 0.29 & 0.63 & 0.29 & 2.77 \\
$\beta$ - Pinene & 1.61 & 0.61 & 0.26 & 3.45 \\
Sabinene & - & 0.26 & - & 1.51 \\
$\alpha$ - Phellandrene & 0.43 & 0.14 & 0.65 & 4.92 \\
Myrcene & - & 2.70 & 0.77 & 0.43 \\
$\alpha$ - Terpenene & 0.08 & 1.30 & 1.10 & 1.05 \\
Limonene & 1.0 & 1.2 & 0.3 & 6.2 \\
$\beta$ - Phellandrene & 0.07 & - & - & 2.09 \\
(Z)- $\beta$-Ocimene & 0.03 & 0.14 & - & 0.28 \\
$\gamma$ - Terpenene & 0.05 & 0.16 & - & 0.57 \\
(E)- $\beta$ - Ocimene & 0.02 & 0.13 & - & 0.94 \\
p-Cymene & 0.01 & 1.91 & 0.92 & 1.38 \\
Terpinolene & 0.30 & 0.21 & 0.61 & 0.47 \\
Linalool & 0.08 & 3.70 & 2.77 & 0.13 \\
Terpinen-4-ol & 0.27 & 0.40 & 0.11 & 1.90 \\
$\alpha$ - Terpineol & 0.64 & 0.70 & 0.28 & 3.94 \\
$\alpha-$ Fenchyl alcohol & 0.41 & - & - & - \\
Isoborneol & 0.70 & 0.08 & - & 0.68 \\
Sabinol* & - & - & 0.20 & - \\
\hline & & & & \\
\hline
\end{tabular}




\begin{tabular}{|c|c|c|c|c|}
\hline \multirow[t]{2}{*}{ Compound } & \multicolumn{4}{|c|}{ Relative abundance } \\
\hline & Fruit & Bark & Leaf & Root \\
\hline 1,8-Cineole & 0.05 & 4.60 & 0.51 & 6.39 \\
\hline Methyl chavicol & - & - & - & 0.19 \\
\hline P-Cymen-7-ol & - & - & - & 0.06 \\
\hline Cinnamyl alcohol & - & 0.16 & 0.09 & 0.12 \\
\hline 2-Phenylethyl alcohol & - & 0.47 & - & - \\
\hline Coumarin & - & 0.36 & - & - \\
\hline Benzaldehyde & 0.50 & 0.61 & 0.14 & - \\
\hline Hydrocinnamaldehyde & - & 0.80 & 0.12 & 0.09 \\
\hline Camphor & - & - & - & 47.42 \\
\hline Piperitone & - & - & - & 0.24 \\
\hline 2-Phenylethyl acetate & - & 0.18 & - & 0.05 \\
\hline 3-Phenylpropyl acetate & - & 0.38 & - & 0.03 \\
\hline Cinnamaldehyde & 0.3 & 50.5 & 2.7 & 0.1 \\
\hline Methyl cinnamate & - & 0.27 & 0.09 & 0.10 \\
\hline (Z)-Cinnamyl acetate & 0.10 & 8.78 & 1.00 & 0.12 \\
\hline Benzyl benzoate & - & 1.10 & 4.01 & 0.16 \\
\hline Eugenyl acetate & 1.00 & 0.40 & 0.64 & 0.10 \\
\hline Linalyl acetate & - & - & - & 0.60 \\
\hline Eugenol & 0.45 & 4.15 & 76.74 & 0.21 \\
\hline Methyl isoeugenol ${ }^{*}$ & 0.22 & - & - & - \\
\hline Isoeugenol* & 0.32 & 0.08 & 0.07 & 0.04 \\
\hline Safrole & 0.32 & 0.08 & 0.08 & 1.32 \\
\hline Methyl eugenol & 1.79 & 0.15 & - & 0.12 \\
\hline Methoxy eugenol & - & - & - & 0.17 \\
\hline$\alpha$-Cubebene & 0.20 & - & - & 0.68 \\
\hline$\alpha$ - Ylangene & 2.71 & 0.70 & 0.14 & 0.03 \\
\hline$\beta$ - Caryophyllene & 5.63 & 8.00 & 3.47 & 0.62 \\
\hline$\alpha$-Humulene & 1.41 & 1.30 & 0.57 & 0.12 \\
\hline$\beta$-Cubebene & 1.08 & - & - & - \\
\hline$\beta$ - Farnesene ${ }^{*}$ & 1.58 & - & - & - \\
\hline$\alpha$-Gurjujene & 2.32 & - & - & - \\
\hline
\end{tabular}




\begin{tabular}{|c|c|c|c|c|}
\hline \multirow[t]{2}{*}{ Compound } & \multicolumn{4}{|c|}{ Relative abundance } \\
\hline & Fruit & Bark & Leaf & Root \\
\hline$\beta$-Cadinene & 2.78 & - & - & - \\
\hline$\beta$ - Gurjujene & 0.70 & - & - & - \\
\hline$\alpha$ - Muurolen & 4.40 & - & - & - \\
\hline \multicolumn{2}{|c|}{$\delta$ - Cadinene and $\gamma$-Cadinene 36.00} & - & - & - \\
\hline Cadina-1,4-diene & 1.59 & - & - & - \\
\hline$\alpha$-Cadinene & 5.64 & - & - & - \\
\hline Calamenene $^{*}$ & 0.17 & - & - & - \\
\hline Bisabolol* & 0.35 & - & - & - \\
\hline Nerolidol $^{*}$ & 0.84 & - & - & - \\
\hline$\alpha$ - Cadinol & 1.12 & - & - & - \\
\hline Elemol & 0.13 & - & - & - \\
\hline Sequiphellandrol ${ }^{*}$ & 0.30 & - & - & - \\
\hline T-Cadinol & 7.70 & - & - & - \\
\hline T-Muurolol & 1.05 & - & - & - \\
\hline
\end{tabular}

${ }^{*}$ Correct isomer not identified

Table 2 : Relative abundance of monoterpene, phenyl proponoid and sesquiterpene fractions in Cinnamon bark, leaf, root bark and fruit oils.

\begin{tabular}{lrrrr}
\hline Fraction & Bark & Leaf & Root & Fruit \\
\hline Monoterpenes & 25.3 & 6.7 & 95.2 & 6.7 \\
Phenyl propanoids & 64.8 & 85.4 & 2.2 & 0.9 \\
Sesquiterpenes & 8.7 & 4.7 & 0.7 & 83.6 \\
\hline
\end{tabular}

\section{DISCUSSION}

Two columns of different polarity were used to analyze the essential oils of C. zeylanicum (Supelcowax-10 and SPB-1). Though the major components were identified on both columns, the resolution of constituents was generally better on the supelcowax-10 column.

The modified Likens and Nickereson apparatus was used to trap low volatile constituents of the essential oils. Most of the constituents of the essential oils are terpenes, consisting of monoterpenes, sesquiterpenes and phenylproponoids. Most 
of the terpenoids identified among the leaf, bark and root oils were also detected in the previous studies of the essential oil of C. zeylanicum. ${ }^{5}$

The composition of Cinnamon fruit oil is widely different from Cinnamon leaf, bark and root oils. The oil does not contain high concentrations of components such as eugenol, (E)-cinnamaldehyde and camphor that are major constituents of the leaf, bark and root oils of Cinnamon. The intense, characteristic aroma of Cinnamon fruit oil is therefore most probably due to its sesquiterpene fractions, particularly the major components $\delta$ and $\gamma$-cadinene, cadinol and $\beta$-caryophyllene.

The fruit oil of Cinnamon grown in India was investigated by Jayaprakasha et al and Mallavarapu et al.,7 They reported that the oil from two locations had different compositions. The major constituents of the oil obtained from Kerala region were $\beta$-caryophyllene, and (E)-cinnamyl acetate whereas the oil from Bangalore were $\alpha$-pinene, $\beta$-pinene, $\beta$-caryophyllene, $\alpha$-muurolene, $\delta$ and $\gamma$ - cadinene, and $\alpha$ muulol. The present study indicates that the fruit oil of cinnamon grown in Sri Lanka has a different composition and in particular none of the earlier analyses has indicated $\delta$ and $\gamma$-cadinene (36\%), cadinol (7.7\%) and $\beta$-caryophyllene (5.6\%) as the major constituents.

\section{Acknowledgment}

Financial support from National Science Foundation (RG/87/C/05) of Sri Lanka is gratefully acknowledged.

\section{References}

1 Jayaweera D.M.A. (1980). Medicinal Plants (Indigenous and Exotic) Used in Sri Lanka, pp.117, 3, Publ. National Science Council of Sri Lanka.

2 Laurentius S.F., Wijesekera R.O.B., Devanathan M.A.V., Wijethunge M.H.C., Jayawardena A.L., Ratnasingham.K., Ponnachamy S., Rajendren S. \& Rajathurai P., (1972). Sri Lanka Patent Application NG 6924.

3 De Silva S. (1972). A Report on the Sample Survey of the Cinnamon Industry of Sri Lanka, Ministry of Plantation Industries, Sri Lanka.

4 Senanayake U.M. (1990). Essential oil Product Review. Ceylon Institute of Scientific and Industrial Research. Colombo-07, Sri Lanka.

5 Senanayake U. M., Lee T.H. \& Wills R.B.H. (1978). Volatile constituents of Cinnamomum zeylanicum oils, Journal of Agriculture Food Chemistry, 26: 822-824. 
6 Jayaprakasha G.K., Rao L.J. \& Sakariah K.K. (1997). Chemical composition of the volatile oil from the fruits of Cinnamomum zeylanicum Blum, Flavor and Fragrance Journal 12: 331-333.

7 Mallavarapu G.R. \& Ramesh S. (2000). Essential oil of the fruits of Cinnamomum zeylanicum Blum, Jóurnal of Essential Oil Research, 12: 628630.

8 Paranagama P.A.(1991). Analysis of Sri Lankan Essential oils by Gas Chromatography and Mass Spectroscopy, M.Phil. Thesis, University of Kelaniya, Kelaniya, Sri Lanka. 